\title{
Iglesia, política y opinión pública. Comunicación institucional y comprensión de una realidad
}

\section{Mónica Codina}

Profesora de Deontología de la Comunicación.

Universidad de Navarra

\section{Resumen:}

La pragmática política, legitimada por el voto popular, puede conducir a situaciones de falta de libertad si no se encuentra equilibrada por el desarrollo armónico de todas las dimensiones de la vida social: la religión, la ética y la cultura.

Dentro de un contexto social que tiende a la politización de toda la realidad pública, es necesario pensar sobre el papel que la comunicación institucional de la Iglesia como medio de expresión de su identidad y sobre el trabajo de los profesionales de la comunicación como posibilidad de cooperación en la creación de una opinión pública sensible hacia el bien del hombre.

Palabras clave:

Libertad, política, religión, opinión pública, iglesia, democracia.

\section{Abstract:}

The political praxis, legitimized by popular support, can lead situations of absence of freedom. Especially when there is not a balanced development of all the social dimensions: religion, ethics and culture.

Within a social context, which tends to make a political issue from all the public sphere, it is necessary to think about the role of the institutional communication of the Church as a way to express its identity, and about the work of the professionals of communication as possibility of cooperation in building public opinion according to human being. 
Key words:

Freedom, politics, religion, public opinion, Church, democracy.

\section{Políticas democráticas y libertad religiosa}

La comprensión de los sistemas políticos democráticos como alternancia de partidos ${ }^{1}$ tiende a generar situaciones de dominio pragmático sobre la vida pública, y puede provocar posiciones que ahoguen la libertad. El voto popular justifica el ejercicio de poder, aunque éste no sea acertado ${ }^{2}$. ¿Qué puede medir el valor de las decisiones políticas? Resulta necesario reconocer la supremacía de la religión, la ética y la cultura si se quiere encontrar una medida para la vida política ${ }^{3}$.

La declaración Dignitatis humanae sobre la libertad religiosa (Vaticano II, 1965), subraya la necesidad de poner límite al ejercicio del poder público, de modo que no obstaculice la acción libre y responsable del hombre. En este sentido, la libertad social es posible si la libertad religiosa es una realidad, si no se da una coacción civil que impida o imponga la adhesión a una determinada fe religiosa. Si resulta peligrosa la integración unitaria de política y religión -que convierte a la religión en instrumento de la política o suscita una actividad política integrista-, también es peligrosa la exclusión de la religión de la vida pública de los pueblos, dejándolos sometidos al vaivén de las decisiones pragmáticas de un gobierno que, probablemente, quiere sostener su permanencia en el poder ${ }^{4}$.

La coexistencia armónica de todos los elementos que constituyen la vida pública, proporciona el clima adecuado para el crecimiento de las personas y el desarrollo de las sociedades. Por el contrario, la tendencia a la politización de la realidad social, convierte la división política en criterio último de juicio sobre la legislación, la economía, la cultura, las relaciones internacionales, etc., de tal modo que la pragmática política se constituye en un peligroso criterio de interpretación y decisión. La libertad religiosa, el desarrollo de la cultura o la educación forman parte del núcleo de la polis, y, por tanto, de alguna forma deben ser organizadas, gobernadas, pero no pueden estar exclusivamente tuteladas por el interés político, ya que son realidades humanas fundamentales que no pueden ser suplantadas por la gestión gubernamental, sino que la trascienden.

\footnotetext{
${ }^{1}$ Sobre la democracia y los partidos políticos puede consultarse en Panebianco, A. (1990).

${ }^{2}$ En este sentido afirma Ralf Dahrendorf,: "Nunca nos cansaremos de decir que democracia y Estado de derecho no son la misma cosa. Hay democracias sin ley y estados de ley (Rechtsstaat) no democráticos. La constitución de la libertad requiere ambas cosas y, de las dos, el Estado de derecho es la más difícil de establecer y mantener, pues no requiere solamente una constitución, sino también -y resulta casi más importante- un poder judicial independiente que sea sensible a las violaciones de las normas constitucionales y otras normas legítimas", La Vanguardia, 23/11/2005.

${ }^{3}$ Un estudio detallado de la relación entre religión, sistemas políticos y desarrollo de las libertades en Ratzinger, J. (1987): pp. 179-202.

${ }^{4}$ Una discusión sobre el papel de la religión en la vida pública en Cnann, R. (1999).
} 
La Iglesia es portadora de una verdad sobre el hombre, que debe mostrar, pero que no puede imponer. Esta verdad capacita al hombre para pensar adecuadamente, desde una nueva perspectiva, la realidad que le es contemporánea. Ahora bien, si la Iglesia quiere incidir en la vida social y, por tanto, en la formación de la cultura, debe comunicar su mensaje, sin cambiarlo, atendiendo a la situación y a la lógica del mundo contemporáneo.

En cada momento de la historia, la Iglesia y el cristiano han tenido que pensar la realidad humana emergente a la luz de la fe revelada. La apuesta por un sentido laico del estado, la confluencia creciente de la diversidad cultural y religiosa -debida a los movimientos migratorios- y el liberalismo moral, son algunas de las causas que originan el intenso debate que ha precedido la redacción del Tratado por el que se establece una Constitución para Europa. Uno de los puntos álgidos de la discusión política e intelectual se encuentra en la oportunidad de realizar una mención explícita en dicho tratado de las raíces cristianas de la cultura europea, lo que pone de manifiesto que la Iglesia y el cristiano se encuentran ante un nuevo desafío.

Si el contenido de la fe tiene valor para el mundo contemporáneo, surgen espontáneamente dos preguntas: ¿Cómo debe ser la comunicación de la Iglesia dentro del contexto social actual para alcanzar un impacto adecuado en la formación de la opinión pública? Y, ¿cómo puede el profesional de la comunicación y los cristianos en general contribuir eficazmente a la creación de una opinión pública sensible hacia el bien del hombre?

\section{La comunicación institucional de la Iglesia}

La primera cuestión, de modo inmediato, se dirige a considerar cómo la Iglesia puede dar a conocer y hacer que se respete su identidad ${ }^{5}$ dentro de un entorno social en que quedan algunas manifestaciones culturales del catolicismo, dentro de un ambiente que tiende de forma interesada a confundir la aconfesionalidad con el laicismo, la libertad religiosa con la indiferencia y el respeto a las distintas identidades culturales con el relativismo cultural. La respuesta que se otorgue a este primer reto, no puede prescindir del origen sobrenatural de la Iglesia y de su naturaleza jerárquica.

La Iglesia tiene su origen en los actos fundacionales de Cristo, quien la instituye con una estructura jerárquica $^{6}$. El que pertenece a la Iglesia, pertenece a Cristo y participa de su misión ${ }^{7}$. Ahora bien, la misión de ejercicio de los tria munera de Cristo tiene un alcance distinto entre los fieles, esto es, su ejercicio compete de diferente manera a quienes han recibido el don del sacerdocio ministerial ${ }^{8}$. En este

\footnotetext{
${ }^{5}$ Sobre la naturaleza, función y misión de la comunicación institucional en este sentido, cfr. Sotelo, C. (2001): pp. 23-30.

${ }^{6}$ Cfr. Lumen gentium (1964): n. ${ }^{\circ} 18$; Catecismo de la Iglesia Católica (1992): n. ${ }^{\circ} 874$.

${ }^{7}$ Cfr. Catecismo de la Iglesia Católica (1992): n. ${ }^{\circ}$ 75-78.

${ }^{8}$ Sobre el modo en que los fieles laicos participan de la misión que Cristo ha confiado a su Iglesia, cfr. Catecismo de la Iglesia Católica (1992): n. ${ }^{\circ} 897-913$.
} 
sentido, la incidencia de la Iglesia en la formación de la opinión pública se debe ejercer desde una doble dimensión.

En cuanto la Iglesia realiza una comunicación de carácter institucional, sólo puede estar representada por quienes tienen poder de gobierno y magisterio en las condiciones establecidas ${ }^{9}$. Esto es, el Papa y los obispos en comunión con el Papa, o en su formalización territorial en cuanto Conferencia epis$\operatorname{copal}^{10}$. El modo en que esta comunicación se puede llevar a cabo es muy diverso y su grado de representación institucional, así como su carácter vinculante, se deben juzgar con los criterios establecidos por la Iglesia, para emitir un juicio sobre su magisterio ordinario ${ }^{11}$. En todo caso, resulta evidente que sólo la comunicación realizada por la jerarquía de la Iglesia en cuanto tal, aunque lo haga por medio de un portavoz, sea este sacerdote o laico, tiene carácter institucional ${ }^{12}$. En ningún caso la comunicación realizada por un fiel cristiano puede ser hecha en representación de la Iglesia, a no ser que se actúe delegadamente, como portavoz: en sentido literal, llevando la voz de otro.

En el contexto actual, la Iglesia en cuanto institución que goza de una amplia e incisiva vida pública, no puede prescindir de realizar una comunicación institucional profesionalizada, ya que debe dar a conocer su identidad y su misión dentro del mundo. Forma parte de su ser en el mundo usar las formas de comunicación que son corrientes en cada época. "La Iglesia tiene la necesidad y el derecho de dar a conocer las propias actividades, al igual que hacen otras instituciones o grupos, pero al mismo tiempo, cuando sea necesario, debe poder garantizar una adecuada reserva, sin que ello perjudique una comunicación puntual y suficiente de los hechos eclesiales" (Carta apostólica del sumo Pontífice Juan Pablo II a los responsables de las comunicaciones sociales, 2005: $\left.\mathrm{n} .^{\circ} 12\right)^{13}$.

Dentro de un contexto adverso a las manifestaciones públicas de adhesión a la fe religiosa, cuando la afirmación de verdades definitivas y el compromiso moral se consideran excesivos, la Iglesia necesita

9 "El fenómeno actual de las comunicaciones sociales estimula a la Iglesia hacia una especie de revisión pastoral y cultural que le haga capaz de afrontar, de manera adecuada, el cambio de época que estamos viviendo. Son los Pastores, sobre todo, quienes deben hacerse intérpretes de esta exigencia: es importante preocuparse de que la propuesta del Evangelio se haga de modo incisivo y promueva su escucha y acogida", Carta apostólica del sumo Pontífice Juan Pablo II a los responsables de las comunicaciones sociales (2005): $\mathrm{n} .^{\circ} 8$.

${ }^{10}$ Sobre el carácter colegial del ministerio eclesial, cfr. Catecismo de la Iglesia Católica (1992): n. ${ }^{\circ} 877$ y 880-887.

${ }^{11}$ Cfr. Lumen gentium (1964): n. ${ }^{\circ} 25$ y Catecismo de la Iglesia Católica (1992): n. ${ }^{\circ}$ 891-892.

${ }^{12}$ José María La Porte ha destacado el papel integrador de una comunicación bien gestionada, cfr. La Porte, J. M., (2003): pp. 378-379.

${ }^{13}$ Y sigue "ya que, como subraya oportunamente el Concilio, 'de este trato familiar entre los laicos y pastores se esperan muchos bienes para la Iglesia: así se robustece en los seglares el sentido de su propia responsabilidad, se fomenta el entusiasmo y se asocian con mayor facilidad las fuerzas de los fieles a la obra de los pastores. Estos últimos, ayudados por la experiencia de los laicos, pueden juzgar con mayor precisión y aptitud tanto los asuntos espirituales como los temporales, de suerte que la Iglesia entera, fortalecida por todos sus miembros, pueda cumplir con mayor eficacia su misión en favor de la vida del mundo"'. 
contar con una programa de comunicación y con un equipo de profesionales capaz de llevarlo a cabo ${ }^{14}$. No se trata de una estrategia que olvide su carácter sobrenatural, sino de un trabajo profesional que alcance unos objetivos claros en la comunicación, que facilite el conocimiento de su realidad y de sus acciones en la esfera pública.

Para poder desarrollar este programa de comunicación institucional, es necesario determinar los contenidos que se quieren transmitir y conocer con profesionalidad el funcionamiento de los medios de comunicación. La determinación de los mensajes y el conocimiento de la profesión son indispensables para poder actuar oportunamente. Es necesario tener en cuenta que un error en comunicación puede ser causa de confusión, escándalo o motivo fácil de crítica o ironía sobre la Iglesia. Por lo que, la configuración de un programa de comunicación institucional por parte de la Iglesia ya no es sólo cuestión de estrategia sino de responsabilidad moral ${ }^{15}$.

La complejidad de las situaciones que hoy se plantean es evidente: ¿debe reaccionar institucionalmente la Jerarquía ante la publicación de un libro como El código da Vinci?; ¿cómo se deben afrontar algunas situaciones que son ocasión de escándalo?; ¿ cómo puede intervenir en los debates públicos sobre cuestiones morales que requieren una respuesta rápida y contundente carente de popularidad? Si la comunicación no se desarrolla de modo adecuado se pueden producir graves efectos contraproducentes: generar escándalos innecesarios, hacer publicidad indirecta de materiales que no son cristianos, propiciar situaciones de incertidumbre o confusión, en definitiva, desfigurar la imagen de la Iglesia y de la vida cristiana.

Cualquier declaración que se realiza a través de los medios de comunicación llega a un público amplio, diverso, que no puede preguntar. Los mensajes se amplifican en direcciones insospechadas y con frecuencia se interpretan dentro de un imaginario social estereotipado. La práctica habitual de todas las instituciones es desarrollar un programa de comunicación que tiene por objetivos facilitar el conocimiento de su identidad y de sus acciones, la transparencia en la gestión interna y económica, poner al alcance de los ciudadanos y particularmente de las personas vinculadas a la institución un conocimiento cercano y verdadero de su realidad. Por tanto, la comunicación institucional no se entiende hoy como una estrategia de defensa ante situaciones de crisis sino, más bien, como un dar a conocer, adelantarse a los problemas y explicarse.

La Iglesia -universal y local- necesita tener su propio programa informativo y trabajarlo con profesionalidad. Un programa positivo que no se limite a defenderse de los ataques, sino que trabaje su

${ }^{14}$ Dentro del ámbito anglosajón, autores destacados de la conocida como disciplina de Relaciones Públicas, han enfatizado la necesidad de una planificación en las acciones de comunicación, cfr. Cutlip, S.; Center, A.; Broom, G., (2000): pp. 339-456. También, Weintraug Austin, E.; Pinkleton, B. E. (2001).

${ }^{15}$ Las acciones de comunicación, en cuanto actividad organizada, permiten precisamente hacer partícipes a los públicos, cfr. Sotelo, C. (2001): pp. 201-205. 
propia agenda de comunicación, que determine de qué quiere hablar y se preocupe de comunicar su imagen en modo adecuado a su verdad. Para elaborar este programa puede ser necesario contar con una oficina de prensa profesional y un portavoz oficial -que se trate de un laico, un sacerdote o una persona consagrada, depende de las condiciones de las personas y de la sociedad-. En todo caso, un portavoz debe ser un profesional de la comunicación, y con la misma profesionalidad conocer bien la doctrina teológica, la moral, las costumbres y el derecho de la Iglesia. Aunque, en rigor, también se podría decir que un portavoz debe ser un profesional de la doctrina y de la moral de la Iglesia, explicadas con acierto práctico para el mundo contemporáneo, usando profesionalmente las técnicas contemporáneas de la comunicación.

La comunicación de la Iglesia se hace para profesionales y personas que no tienen particular conocimiento de su identidad, a veces se acercan desde una imagen distorsionada o incluso con una actitud adversa. Esto condiciona las características y el modo de transmisión de los mensajes que deben ser pocos, claros, entendibles en su contenido por todos y positivos. Forma parte también del trabajo de la oficina de prensa conocer y tratar a los profesionales de la comunicación que deben ser transmisores de la información. Esta cercanía facilita el trabajo profesional, nunca es una labor de control. La lógica de la comunicación institucional indica que el profesional de la información no confía en la institución si la institución no confía en su trabajo.

Son variados los criterios y las acciones que pueden orientar esta agenda de comunicación. El calendario litúrgico y las fiestas populares son ocasión natural para determinar temas concretos de evangelización, así mismo, algunos temas de carácter moral y con fuerte incidencia en la vida pública deben ser trabajados de tal modo que los mensajes se transmitan de modo eficaz, claro, en el momento y con la periodicidad oportunos, adelantándose a las situaciones de conflicto que se van a presentar. Dentro de este ámbito se encuentran todas las cuestiones referentes a la educación, investigación científica, origen y final de la vida, libertad religiosa, etc.

Son dos los niveles en que la Iglesia tiene que hacer esta comunicación, el primero y más importante, es la dirigida a los fieles practicantes, que con frecuencia se sitúa en una predicación dominical planificada. Al mismo tiempo, el modo en que se ha desarrollado el magisterio de Juan Pablo II, ha puesto de manifiesto que la Iglesia es custodia de una verdad sobre el hombre que tiene validez universal y que debe transmitir institucionalmente y hacer valer en la vida pública, por lo que es necesario desarrollar los mecanismos que permitan comunicar públicamente esta verdad.

En gran medida, el trabajo realizado por la oficina de prensa del Vaticano durante los días de la agonía y fallecimiento de Juan Pablo II, así como la elección de Benedicto XVI, han puesto de manifiesto que cuando se nutre de información verdadera a los profesionales de la información se deja poco espacio para la especulación. En este sentido, cabe destacar la prontitud y exactitud con que se publicaron las notas de prensa durante esos días; los SMS enviados a todos los profesionales acreditados con la noticia 
del fallecimiento del Santo Padre, sin privilegiar a ninguna empresa de comunicación; las dos ruedas de prensa especiales que se convocan para explicar la situación en que queda el gobierno de la Iglesia en periodo de sede vacante y el significado de los ritos de misa de exequias, así como toda la información que se prepara desde la Sala de prensa del Vaticano para explicar en qué consiste el desarrollo del Cónclave, han sido muestra de un trabajo profesional riguroso y eficaz.

En este caso particular, sin duda, la realidad de la Iglesia es lo primordial: la vida y la muerte santa de Juan Pablo II, la multitud congregada en oración acompañando al Santo Padre en su agonía, el modo sencillo en que la plaza de San Pedro se anuncia que el Santo Padre se ha ido a la casa del cielo, la realidad de una Iglesia orante en el mundo entero, la unidad del colegio cardenalicio y la naturalidad y sentido con que los cardenales electores guardan el silencio de oficio. Esta realidad acompañada por una comunicación institucional moderna, cuidadosa y precisa tiene como resultado un tratamiento correcto de la información, no deja lugar a la especulación, ni da impresión de secretismo.

\section{Contenido de la comunicación}

La comunicación institucional de la Iglesia se encuentra ante el reto de superar dificultades precisas:

1. La identidad de la Iglesia y de sus representantes se comprende hoy con un marcado carácter estereotipado. El uso de tópicos es frecuente como modo de simplificación de la realidad, pero no siempre adecuado a su naturaleza. Por ejemplo, quienes dicen que el pontificado de Juan Pablo II se ha caracterizado por tener un carácter progresista en las cuestiones sociales y conservador en la moral, aplican un razonamiento simple que no resulta de una profundización en todos los elementos que han configurado este pontificado. Atribuyen una versión simple de la interpretación del Concilio Vaticano II que no responde a la Iglesia que ha iniciado un nuevo milenio. En este sentido, es necesario estudiar el modo de vencer en positivo el carácter tópico de la información.

2. Por una razón de justicia, la Iglesia puede y debe dar a conocer sus acciones en favor de los más desfavorecidos. Dentro de la vida eclesial existe una multiplicidad de instituciones, asociaciones y personas que realizan un trabajo de servicio a los pobres y enfermos, o se dedican al cuidado del patrimonio cultural que nace ligado en el tiempo a la vida de la Iglesia, o que realizan la defensa de la vida, los derechos humanos o la familia. Aunque el espíritu evangélico no busque la publicidad, habrá ocasiones en que se tendrán que presentar datos de orden numérico y económico que contrasten las políticas dominantes o los ataques a la fortaleza moral que mantiene la Iglesia.

3. La comunicación institucional de la Jerarquía debe responder a cuestiones que periódicamente adquieren especial relevancia en el debate público. Por ejemplo, es necesario explicar cómo se 
sostiene económicamente la Iglesia, la inversión que realiza en mantenimiento del patrimonio o de centros de carácter educativo o asistencial. De tal modo que los datos, quizá mediante la publicación y presentación a los medios de comunicación de un informe económico anual, orienten el juicio de los fieles y de quienes quieran contribuir al desarrollo de alguna de sus actividades. Esta transparencia económica debe ofrecerse a través de medios públicos, con datos precisos. No es suficiente que sea algo cognoscible, sino que debe darse a conocer: cómo es el funcionamiento de las cuentas en el Vaticano, la inversión y financiamiento de las escuelas concertadas y privadas, el sostenimiento de las obras sociales, el mantenimiento del patrimonio, de los edificios, de las iglesias y del clero. Todas son cuestiones de las que se hace necesario informar y que ayudan a ver una transparencia en la gestión, a emitir juicios acertados respecto las políticas de gobierno o a adquirir un compromiso de colaboración con el sostenimiento de la Iglesia, así como abren la posibilidad de contar con la colaboración de los no cristianos ${ }^{16}$. Una campaña que pide la señalización de la casilla que destina la contribución a la Iglesia es insuficiente, no hace valer adecuadamente los fines a los que se va a destinar ese dinero. Ciertamente la Iglesia no busca hacer publicidad de su caridad, pero no puede prescindir de mostrar su realidad social porque sería ocasión de injusticia.

4. La jerarquía debe ayudar a clarificar los estados de confusión en la opinión pública, proporcionando los informes que sean necesarios. Los datos pueden contribuir a moderar los juicios, por ejemplo, los de quienes juzgan que la Iglesia permite con sus propuestas morales la transmisión de enfermedades como el sida. Las políticas de promoción de la abstinencia como medio de prevención con resultados efectivos o la asistencia por parte de centros eclesiales a un número considerable de enfermos de sida, son motivo suficiente para contrarrestar una imagen errónea.

También es necesario analizar los escándalos que se producen en sus miembros. En este sentido, el pontificado de Juan Pablo II no ha querido ocultar algunas situaciones difíciles y ha indicado la necesidad de proporcionar datos y hacer públicas de modo inmediato las medidas de gobierno oportunas en cada caso. La verdad puede ser dolorosa, pero es necesario afrontarla.

5. Es necesario considerar que la unidad de mensaje, manifestado por quienes en la Iglesia tienen misión de gobierno, lo hace más fuerte: unidad en la fe, en la doctrina, en la moral y de las personas dentro de la Iglesia. Esta unidad también se debe manifestar a través de la diversidad de formas de comunicación, cuando quien habla participa de una peculiar misión dentro de la Iglesia, aunque in actu no actúe en su nombre. La prudencia exige unidad de mensaje en el episcopado, saber cuándo es necesario hablar y cuando callar, conocer las técnicas de comunicación para actuar con prudencia, como elementos necesarios para realizar una buena co-

\footnotetext{
${ }^{16}$ Recientemente un estudio señalaba el ahorro económico que supone al Estado la educación concertada.
} 
municación. La opinión pública quiere conocer el juicio de la Iglesia de modo preciso y los medios de comunicación normalmente no son el lugar propio para discusión de los diferentes pareceres que pueden existir de modo legítimo en un momento dado.

6. Es preciso gestionar a tiempo las dificultades sociales. La lógica de la comunicación y del razonamiento humano indican que el pensamiento se desenvuelve mejor cuando se alimenta de modo desapasionado. Normalmente las tendencias sociales de opinión, las políticas de los gobiernos, los retos de la investigación, así como las diversas situaciones en que se pone en juego el respeto a la persona se acercan y preparan en el tiempo. Las acciones de comunicación institucional no pueden esperar a encontrarse con el problema en su momento álgido, sino que deben adelantarse, siempre que sea posible, a su aparición y trabajar con anticipación en la configuración de la opinión pública. No es difícil determinar cuáles son los temas donde se debe incidir.

7. Gestionar la comunicación no significa manipulación ni éxito, sino trabajo serio y planificado. La comunicación institucional de la Iglesia forma hoy parte ineludible de su misión y, por tanto, mantiene las características de ésta, debe hacerse en verdad y con libertad.

En definitiva, afirma Juan Pablo II, la Iglesia está llamada a integrar su mensaje en la "nueva cultura" que los medios de comunicación crean y amplifican. "La Iglesia advierte que el uso de las técnicas y tecnologías de comunicación contemporáneas forman parte de su propia misión en el tercer milenio" (Carta apostólica del sumo Pontífice Juan Pablo II a los responsables de las comunicaciones sociales, 2005: $n .^{\circ} 2$ ).

\section{Las acciones de comunicación del cristiano dentro de la sociedad civil}

El segundo elemento que se debe considerar, no menos importante, es el de la acción profesional en el ámbito de la comunicación; esto es, cuál es el papel del cristiano en el ámbito de la comunicación dentro de la sociedad civil. Y, en particular, cómo debe ser la actuación del profesional de la comunicación que quiere contribuir a crear una vida pública donde, cada vez más, esté presente el bien del hombre.

Si la primera consideración que se debe realizar es que cada uno tiene su propio camino dentro del mundo y de la Iglesia, es necesario añadir que la tarea de lograr por medio de las profesiones de comunicación una profunda contribución al bien de los hombres es una responsabilidad solidaria que los cristianos asumen junto a otros profesionales.

El trabajo del profesional de la comunicación se dirige a dar a conocer a los ciudadanos las realidades sociales, políticas, económicas, culturales y religiosas de modo que estos puedan conocer, valorar y decidir sobre la realidad. Este trabajo precede y pone las condiciones de recepción de toda comunicación institucional de la Iglesia. Una labor profesional realizada con una sensibilidad atenta al bien del hombre, facilita las condiciones de recepción y comprensión del mensaje cristiano. 
El trabajo del profesional de la comunicación se entrelaza, como un elemento más, en la configuración de la vida pública, generando un amplio espacio para la opinión política, el impulso de la economía o las diferentes propuestas culturales. Es una plataforma privilegiada para impulsar la creación y el fortalecimiento de la sociedad civil.

\section{El desarrollo de la democracia}

La democracia es un sistema de gobierno que tiene su propio grado de imperfección: en cuanto sistema, es deficiente como toda forma humana de gobierno; en la medida en que se realiza según la conciencia de quien asume una determinada competencia, depende de la honestidad de quien tiene el poder; $y$, además, queda sujeto al grado de competencia humana y profesional de la que goce el gobernante. Esto significa que el sistema no garantiza por sí solo un buen gobierno, aunque pueda proporcionar ciertas condiciones más o menos favorables, sino que en última instancia su valor es correlativo al de las acciones de las personas que gobiernan.

Si las políticas sociales impulsadas por un gobierno tienden a provocar situaciones de laicismo, esto es, de persecución contra la manifestación pública de lo religioso, se constituye de hecho una forma de estado totalitario, que tiende a reducir la vida social a la discusión política. La economía, la cultura, la educación y la religión quedan bajo el dominio de las decisiones políticas, se someten a los criterios de una ideología, y no se puede encontrar una realidad superior que pueda juzgar las decisiones políticas del gobierno dominante. El sistema democrático se convierte en una forma de totalitarismo que sólo se puede superar si crecen otros aspectos de la vida social, aquellos que conforman el auténtico sentido de la polis, tal y como se entiende en la antigua Grecia.

Contribuir desde las profesiones al desarrollo del sistema político denominado democracia puede ayudar a hacer más efectiva la presencia de la Iglesia en la vida pública. En este sentido se puede alcanzar un mayor desarrollo de la vida pública en varias direcciones:

1. Es necesario ampliar la formación política de los ciudadanos. Más allá de la conciencia de la importancia del voto, está la idea creciente de la participación ciudadana en la configuración de la vida pública.

2. Urge consolidar una separación real de poderes -ejecutivo, legislativo y judicial- de modo que no quede en dependencia de la política los nombramientos y la validez de las decisiones tomadas. Este objetivo sugiere la necesidad de recuperar el sentido de la conciencia corporativa profesional, el espíritu con que se ejercita el ejercicio de ese poder, que actúa como garante de la independencia ante la diversidad de tendencias políticas.

3. Es conveniente alimentar el sentido de la competencia profesional como criterio de decisión sobre la mayoría de los asuntos públicos. Educación, medicina, estudios técnicos, patrimonio o 
cultura son realidades sociales que se apoyan en saberes definidos y que, por tanto, no pueden someterse a los vaivenes de la opinión política.

4. La no ingerencia de la política en la totalidad de la res pública, esto es, en términos prácticos: potenciación de la cultura, la educación y la vida social más allá de las decisiones de partido.

5. Contribuir al desarrollo de las empresas de comunicación procurando que desempeñen el servicio que les compromete ante los ciudadanos. Para realizarlo, no sólo debe quedar garantizada su independencia económica y política, los derechos fundamentales que regulan la libertad de prensa, sino que se debe gobernar para que los derechos de los ciudadanos no se vean conculcados. Se trata de una tutela adecuada, pero no de una dependencia política que permite situaciones de dominio ${ }^{17}$.

6. El desarrollo de la libertad religiosa, que se entiende como respeto a la diversidad y no nace de la indiferencia, que conduce al nihilismo, sino del compromiso con un credo determinado.

7. La primacía de la ética sobre la política. De modo que la sociedad valore primordialmente la ética humana y se promueva la exigencia política de salvaguardar de modo adecuado la moral pública, sin la que no se puede construir la sociedad.

Consideradas así las cosas, se podría pensar, ¿qué queda para los políticos? Son muchos los aspectos que se pueden gestionar por un gobierno: relaciones con otros países, políticas de desarrollo económico, coordinación de las diferentes instituciones, etc., propiciando una gestión autónoma de la cultura y de la diversidad de iniciativas civiles. Desde este punto de vista, el trabajo de los profesionales de la comunicación cobra particular relieve, pues tiene a su alcance potenciar el crecimiento de la sociedad civil. Cabe destacar que la última Carta apostólica del sumo Pontífice Juan Pablo II a los responsables de las comunicaciones sociales, del 24 de enero de 2005 fortalece la dimensión humana de los aspectos de comunicación social frente a una consideración meramente técnica o instrumental de sus potencialidades $^{18}$. Efectivamente las nuevas tecnologías han permitido que se configure un nuevo modo de comunicación humana, que todavía se expande, y que está generando un nuevo modo de formación de la cultura. Ya que, como señala la carta, muchos momentos de la existencia humana se articulan a través

${ }^{17}$ La situación actual de los contenidos de la televisión en Europa fomenta una cultura vulgar, que facilita el dominio político sobre la sociedad.

18 "En la Carta encíclica Redemptoris missio he querido subrayar, que el primer areópago de los tiempos modernos es el mundo de la comunicación, capaz de unificar a la humanidad convirtiéndola, como se suele decir, en "una aldea global”. Los medios de comunicación social han alcanzado tal importancia que para muchos constituyen el principal instrumento de guía y de inspiración en su comportamiento individual, familiar y social. Se trata de un problema complejo, puesto que tal cultura, aún antes que por "los contenidos", nace por el hecho de que existen nuevos modos de comunicar con técnicas y lenguajes inéditos", Carta apostólica del sumo Pontífice Juan Pablo II a los responsables de las comunicaciones sociales (2005): $\mathrm{n}^{\circ} 3$. 
de procesos mediáticos: "la formación de la personalidad y de la conciencia, la interpretación y la estructuración de lazos afectivos, la articulación de las fases educativa y formativa, la elaboración y la difusión de fenómenos culturales, el desarrollo de la vida social, política y económica" (Carta apostólica del sumo Pontífice Juan Pablo II a los responsables de las comunicaciones sociales, 2005: ${ }^{\circ}{ }^{\circ}$ 3). Se trata de un nuevo elemento que se introduce en la formación de la personalidad y la cultura.

Esta situación adquiere un sentido positivo a través del trabajo realizado por los profesionales de la comunicación, cuando éste se propone ayudar en la construcción de una vida social justa y solidaria, colabora en el ejercicio libre y responsable de la libertad ${ }^{19}$. De la comprensión profunda del servicio que el profesional de la comunicación debe prestar a la vida ciudadana, nace el sentido de una auténtica deontología.

La excesiva politización de la labor informativa tiende a oscurecer el conocimiento y la opinión acerca de las realidades sociales. Si es importante saber cuándo un tema debe ser afrontado y cómo, también es importante saber cuándo se debe callar, el silencio también es una forma de la palabra. Forma parte de la competencia del profesional actuar rectamente como gatekeeper, tratando los temas de modo que socialmente se hagan comprensibles y controlando los intentos de manipulación por parte de las fuentes. Informar de modo inteligente es dirigir oportunamente la luz sobre lo importante, llevar la información al punto de luz preciso, no empequeñeciendo la realidad al mostrarla desacertadamente. Por el contrario, cuando no se enfoca con acierto la realidad se corre el riesgo de no informar.

En este sentido, los profesionales pueden contribuir con su trabajo a la formación de la capacidad de discernimiento acerca de los contenidos. Como es lógico, esta tarea exige del profesional una formación intelectual y conocimientos adecuados para emitir un juicio, romper con la ideología y los estereotipos dominantes. Ahora bien, en ningún caso, proporcionar los elementos de conocimiento necesarios que hacen posible establecer un juicio sobre una realidad, significa eliminar las posibles diferencias de opinión, cegar el conocimiento de la diversidad ${ }^{20}$.

\section{Prestar un servicio cualificado a la sociedad civil}

El profesional de la comunicación se compromete a prestar un servicio cualificado a la sociedad civil. Asume una responsabilidad delegada que debe afrontar conscientemente y con la competencia profesional necesaria.

\footnotetext{
19 "Dentro de una visión orgánica y correcta del desarrollo del ser humano, los medios de comunicación pueden y deben promover la justicia y la solidaridad, refiriendo con verdad y cuidado los acontecimientos, analizando en modo completo las situaciones y los problemas, y dando voz a las diversas opiniones. Los criterios supremos de verdad y de justicia, en el ejercicio maduro de la libertad y de la responsabilidad, constituyen el horizonte donde situar una auténtica deontología en el aprovechamiento de los modernos y potentes medios de comunicación social" (Carta apostólica del sumo Pontífice Juan Pablo II a los responsables de las comunicaciones sociales, 2005: . $^{\circ} 3$ ).

20 "Si hay posiciones diversas que entran en confrontación dialógica, es justo porque se comparte el convencimiento de que hay realmente verdad en el ámbito social, y se abriga la esperanza de que se pueda acceder a ella por el recto ejercicio de la inteligencia" (Llano, A., 1999: 203).
} 
Algunos de los aspectos que pueden contribuir a mejorar el trabajo de los profesionales en esta dirección son:

1. Huir del periodismo de declaración. Los políticos saben manejar este procedimiento para convertir el escenario público en plataforma de formación de la opinión pública. El trabajo periodístico exige contrastar y buscar fuentes y documentos de información que sean útiles para alcanzar un conocimiento de la realidad. No es suficiente transmitir opiniones políticas, sino que es necesario trabajar y transmitir datos que permitan a los ciudadanos conocer la realidad y formarse una opinión.

2. Facilitar la reflexión de los ciudadanos. Si bien, en ocasiones, es necesario hacer un periodismo de confrontación, no se puede olvidar que puede suscitar falta de credibilidad y sobre todo, que los momentos en los que el debate público se recrudece por medio del trabajo periodístico, no son propicios para crear un clima de reflexión serena que conforme la opinión pública. El trabajo periodístico exige proporcionar datos con serenidad, adelantarse a los problemas, tratándolos desde los medios antes de que aparezcan ya que normalmente las situaciones de debate o de crispación no favorecen un clima propicio para la reflexión ${ }^{21}$.

3. Mostrar la realidad comunicando el alcance humano de su significado. Es difícil no empequeñecer la dimensión de las realidades humanas al comunicarlas con los modos propios de la comunicación pública, sobre todo si se trata de realidades humanas complejas. En este sentido es importante discriminar adecuadamente donde se encuentra el centro de la información o el debate, de lo contrario se puede empequeñecer la dimensión o el valor de la realidad tratada ${ }^{22}$.

${ }^{21}$ Algunas experiencias lo ponen de manifiesto. En Estados Unidos el debate sobre el aborto se mueve normalmente dentro del contexto de la confrontación pro life/pro choice. Paul Swope director regional de Vitae Caring Foundation ha impulsado una campaña de comunicación que parte de una aproximación diversa a la situación: se propone estar al lado de la joven que quiere abortar para acompañarla y ayudarle a razonar en el momento en que sufre el problema. Cuando la fundación ha activado sus campañas publicitarias a través de la televisión el número de abortos se ha reducido considerablemente. Cfr. www.vitaecaringfoundation.org

${ }^{22}$ Un ejemplo reciente puede ayudar, con motivo del fallecimiento de Juan Pablo II se debate acerca de la reacción del gobierno socialista en España, en concreto sobre la oportunidad de que este realice una declaración pública de condolencia o proclame luto oficial. Si la comunicación se centra en la discusión de este punto se cometería un error: porque la realidad de lo acontecido en Roma es mayor que la decisión de un gobierno que puede no percibir la dimensión del acontecimiento. Si se abre una discusión amplia sobre la reacción de un gobierno se convierte la realidad en una cuestión política y se reduciría el acontecimiento a la nada. Podemos encontrar otros ejemplos, así el debate público acerca del consumo de droga habitualmente se encuadra dentro del ámbito moral o ideológico, cuando constituye un problema grave de salud pública. Del mismo modo se puede entender que no siempre se enfoca con oportunidad enfermedades como el sida, la investigación con embriones, etc. ya que son problemas que no pertenecen sólo al ámbito de la discusión moral, sino que se deben tratar desde una perspectiva científica. Así, por ejemplo, algunos estudios señalan que la vía científica de investigación con células madre embrionarias está cerrada. Cfr. los estudios de David A. Prentice, Ph.D., Adjunct Professor of Medical and Molecular Genetics, Indiana University School of Medicine. 
4. Es necesario contribuir a extender la agenda de temas informativos, de modo que no venga marcada por la agenda política o institucional. En este sentido, tomar la iniciativa para generar nuevos formatos de programas televisivos o radiofónicos en que estén presentes temas atractivos y no sólo la actualidad política es una forma de ampliar el horizonte de la reflexión pública: las tertulias políticas no deberían ser las únicas tertulias. Para lograrlo conviene trabajar sobre la especialización de las personas que colaboran con los profesionales de la comunicación. No todos están preparados para hablar de todo.

5. Es preciso destacar nuevos intelectuales. El profesional puede descubrir personas que por sus condiciones intelectuales pueden contar en el escenario de la vida pública y contribuir a que con su presencia en los medios de comunicación puedan convertirse en líderes de opinión. En determinados casos, también este proceso contribuirá a romper algunos de los estereotipos que conforman de modo inexacto la opinión pública. No se trata de situar a los intelectuales en el ámbito de la derecha o de la izquierda cultural, sino de destacar personas que por su formación, capacidad y talento pueden contribuir a generar nuevas formas de opinión pública.

6. Existen algunas iniciativas que están siendo de gran ayuda en el trabajo informativo sobre la Iglesia y su situación en el mundo. Actualmente goza de gran prestigio la Agencia Internacional de Noticias Zenit que empieza a ser citada como fuente en algunos medios de comunicación.

\section{Cooperadores de la verdad}

Cooperadores de la verdad, es el lema episcopal elegido por el cardenal Ratzinger, hoy Benedicto XVI. La tarea que se contiene en la elección de este lema comprende a la Iglesia de todo tiempo. Proponer sin imponer, cooperando a que se ilumine con verdad la realidad humana, respetando la diversidad y la pluralidad. Esta tarea compete a todo cristiano como parte de su misión en el mundo, ya que con el Bautismo recibe una llamada para ser luz y sal de la tierra. Ahora bien, la tarea de comprender el mundo en su verdad forma parte integrante de la vocación humana universal, por esta razón son muchos los hombres que se encuentran en condiciones de poder cooperar mediante su trabajo profesional en la tarea de comprensión y mejora del mundo.

Los problemas y desafíos que encuentran los profesionales de la comunicación, no se solucionan con al aprendizaje de los nuevos sistemas y de sus efectos, sino que necesitan una comprensión del mundo. La técnica se desarrolla rápidamente engendrando nuevos espacios de dominio y de poder, pero el hombre no alcanza con la misma celeridad el dominio adecuado sobre su propio poder.

La comunicación institucional de la Iglesia no se encuentra sólo ante el reto de explicarse en el contexto de una sociedad que tiende al laicismo, sino que lo debe hacer en un momento que la lógica del mercado mueve el trabajo de las empresas de comunicación. Se trata de una situación de falta de 
salud en las empresas de comunicación, que entran en el juego del servilismo político y económico. Por tanto, la tarea que se pone delante es procurar el nacimiento de una nueva lógica de la comunicación humana. Es necesario trabajar sobre las condiciones en que se dan las nuevas formas de comunicación para comprenderlas mejor y usarlas adecuadamente en servicio del hombre. El desafío que los cristianos comparten solidaria y esperanzadamente con muchos otros hombres: "es el de mantener una comunicación verdadera y libre, que contribuya a consolidar el progreso integral del mundo"(Carta apostólica del sumo Pontífice Juan Pablo II a los responsables de las comunicaciones sociales, 2005: n. $\left.^{\circ}{ }^{13}\right)^{23}$.

\section{Referencias bibliográficas}

- Cnann, R. (1999): The Newer Deal, Social Work and Religión in Partnership, New York: Columbia University Press.

- Cutlip, S.; Center, A.; Broom, G. (2000): Effective Public Relations, Englewood Cliffs: Prentice Hall.

- Dahrendorf, R. (23/11/2005): “Las elecciones no bastan”, La Vanguardia, Barcelona: grupo Godó.

- Juan Pablo II (2005), Carta a los responsables de las comunicaciones sociales, Roma: Librería Editrice Vaticana.

- La Porte, J. M. (2003): "La comunicación institucional como elemento integrador", en Arrese, A. (coord.): Empresa informativa y mercados de la comunicación, Pamplona: EUNSA.

- Llano, A. (1999): Humanismo cívico, Barcelona: Ariel.

- Panebianco, A. (1990): Modelos de partidos. Organización y poder en los partidos políticos, Madrid: Alianza.

- Ratzinger, J. (1987): Iglesia, ecumenismo y política, Madrid: Editorial Católica.

- Sotelo, C. (2001): Introducción a la comunicación institucional, Barcelona: Ariel.

- Vaticano II (1965): Dignitatis humanae. Declaración sobre la libertad religiosa, Madrid: BAC.

- Weintraug, E.; Pinkleton, B. E. (2001), Strategic public relations. Planning and managing effective communication programs, Mahwah: Lawrence Erlbaum Associates.

${ }^{23} \mathrm{Y}$ sigue, "a todos se les pide el saber cultivar un atento discernimiento y una constante vigilancia, madurando una sana capacidad crítica ante la fuerza persuasiva de los medios de comunicación”. 